\title{
DECONSTRUCTING MATULA (TABOO), A MULTI-STAKEHOLDER NARRATIVE ABOUT LGBTI
}

\author{
V. O. Netshandama* \\ Department of Community Engagement \\ e-mail: vhonani.netshandama@univen.ac.za
}

\author{
A. H. Mavhandu-Mudzusi \\ Department of Health Studies \\ University of South Africa \\ Pretoria, South Africa \\ e-mail:mmudza@unisa.ac.za
}

\section{P. Matshidze*}

Department of African Studies

e-mail: pfarelo.matshidze@univen.ac.za

*University of Venda

Thohoyandou, South Africa

\section{ABSTRACT}

This article reports on a multi-stakeholder narrative about the lesbian, gay, bisexual, transgender and intersex (LGBTI) community in Venda in relation to the concept matula (taboo). We used a narrative enquiry design and collected data at a South African rural university using individual, face-to-face interviews with 15 participants (heterosexual and LGBTI individuals), and two focus group discussions with participants from the university and the community. Five themes emerged following narrative analysis, namely: (1) a definition of culture and matula; (2) the construction of the concept of matula, (3) Christian values, interpretations and influence; (4) the tendency to sexualise identity and (5) the knowledge of people about the salient reality of many truths. As there is a tendency of denialism in rural communities, the stories told provide the evidence needed of the presence of LGBTI individuals. We suggest the initiation of culturally congruent LGBTI advocacy programmes in rural areas.

Keywords: bisexual, culture, gay, intersex, lesbian, matula (taboo), transgender

\section{BACKGROUND}

This article reports on a multi-stakeholder narrative about the lesbian, gay, bisexual, transgender and intersex (LGBTI) community in Venda in relation to the use of the concept matula (taboo). Research studies about the stigma, discrimination, hostility and oppressive 
tendencies of LGBTI individuals in schools and other settings have been documented in literature (Francis 2013; Francis and Msibi 2011; Mostert, Myburgh, and Poggenpoel 2012; Reygan 2012; Reygan and Fancis 2015). Some academics have written extensively on the experiences of LGBTI individuals and also the attitudes of heterosexual students towards this population (Mavhandu-Mudzusi and Netshandama 2013; Mavhandu-Mudzusi 2014; Müller 2013). Members of the LGBTI groups have been subjected to stigma and discrimination by heterosexual people based on their sexual and gender orientation (Human Rights Watch 2011). The stigma and discrimination towards LGBTI persons are deeply rooted in cultural and religious beliefs. This leads to stigmatisation and isolation as well as lack of social recognition of LGBTI individuals. Lesbian, gay, bisexual, transgender and intersex persons do not have full access and enjoyment of rights as South African citizens as provided for by the Bill of Rights (Republic of South Africa 1996). Studies have shed some light on the challenges faced by the LGBTI community due to the cultural beliefs held by respective societies. Examples of the challenges highlighted include being judged as being 'bewitched' or 'cursed' (MavhanduMudzusi 2014). Other individuals view being non-heterosexual or being gender nonconforming as un-African (Brouard and Pieterse 2012). A good number of studies have investigated the causes and characteristics of homophobia, but have not studied sufficiently how those practices can be challenged and minimised (Rispel et al. 2012; Müller 2013).

LGBTI individuals are not only experiencing challenges in broader communities, but also in places like universities (Arndt and De Bruin 2006; Human Rights Watch 2009; MavhanduMudzusi 2014; Mavhandu-Mudzusi and Ganga-Limando 2015; Mavhandu-Mudzusi and Sandy 2015). The challenges are mostly experienced in communities where heteronormativity is stressed, such as rural communities and rural universities. According to Collins (2009), heteronormativity relates to a worldview that promotes heterosexuality as the only 'normal' sexual orientation. In this article, we use the term heteronormativity to refer to a set of institutional practices that systematically legitimise and establish heterosexuality as the norm for sexual and broader social relations (Taylor and Snowdon 2014). One such institution where heteronormativity is stressed is at the University of Venda, a South African rural based university.

The Vhavenda is the dominant ethnic group at this university. The studies conducted, and media reports indicate that there is intolerance of any sexual deviation from heterosexuality and cisgender roles as indicated by the extent of stigma and discrimination around LGBTI individuals (DeBarros 2014; Mavhandu-Mudzusi 2014). The intolerance and the bias is evidenced by tendencies to shun and treat those who do not conform to the 'so-called' norm of 
heterosexuality as outcasts, name calling, threats of/actual violence, and all forms of public humiliation (DeBarros 2014; Mavhandu-Mudzusi 2014; Mavhandu-Mudzusi and Sandy 2015). The most common form of humiliation used by most of university members towards LGBTI individuals was the word 'Matula', loosely translated to mean a taboo. In Tshivenda, everything that does not fit into people's reality is often labeled 'Matula'. This prompted us to conduct this study focusing on deconstructing matula in relation to LGBTI individuals. The emphasis was to study the ontology (the nature of being), axiology (set of values - ethics and aesthetic), and epistemology (the origin, nature, methods, and limits of human knowledge) of matula as it applies to the LGBTI community, and to create a space for conversations about LGBTI aspects and the notion of matula in higher education. We undertook to conduct the study because of the realisation that although a lot of work is being done to conscientise communities about the realities of LGBTI, none has attempted to bridge the gap between the understanding of experiences, what is, and the beliefs of people in the surrounding community. The 'unavoidable reality' is that LGBTI individuals are part of the community in institutions of higher education. The university is compelled to accept this population as stipulated in the Constitution of the Republic of South Africa Act 108 of 1996 that everyone has a right of freedom of expression. However, we realised that this was not going to be embraced unless we participated in the space and collected contextual evidence about the experiences of LGBTI individuals on campus. The key narrative that seemed to dominate their interactions with other individuals, in this case was the tendency of other groups to categorise the LGBTI community as doing something ' $z w a$ matula'. These are customary prohibitions or restrictions of a particular practice or forbidding association with a particular person, place, or thing.

We were aware of discriminatory tendencies that are derived from people's perceived realities and thus saw a need for these realities to be deconstructed in a participatory and appreciative manner.

We envisaged that the process and outcome would contribute in overcoming stigma and discrimination against LGBTI students through knowledge generation and discussions about diverse sexual orientations and gender identity. This increased knowledge and understanding may assist in mitigating institutional and societal support for LGBTI students.

\section{THEORETICAL FRAMEWORK}

The study followed the oppression and social justice approach described by Hardiman and Jackson (1997). These authors (1997) identify four conditions for the existence of social oppression: (1) a 'one up group' that has the power to define and determine reality, normality 
and correctness; (2) 'systemic and institutionalised discrimination, harassment, exploitation, marginalisation and other forms of differential treatment'; (3) psychological colonisation of the 'one down group' through socialising them to internalise their oppressed condition and collude with the oppressors' ideology and social system; and (4) misrepresentation, discounting, or even eradication of the oppressed culture, language and history, while imposing the culture of the dominant groups. In this study, the dominant group is the Vhavenda heterosexual community, whilst the LGBTI individuals are the oppressed. This study will focus mainly on the first condition, which is the power to define and determine reality, normality and correctness'. The choice for focusing on the first condition is based on the use of the term, matula, to describe the LGBTI community and means that the Vhavenda culture has its own understanding and definition of reality, normality and correctness in relation to sexual orientation and gender identity.

\section{METHODOLOGY}

\section{Design}

We used a narrative enquiry design. We chose this design as it enabled us to discover the notion of 'matula' in relation to LGBTI community from the Vhavenda point of view, instead of just presuming it.

\section{Study setting}

The study was conducted at a South African rural university in Limpopo. The institution, which was established during the apartheid era, currently caters largely for students from a wide range of local rural Vhavenda communities. The community is heteronormative (promotes heterosexuality as the only 'normal' sexual orientation). Any deviation from 'heterosexuality' is considered a taboo, which may need heterosexualisation (means of converting nonheterosexual individuals back to 'normality').

\section{Sampling and sample size}

We recruited the participants using the purposive sampling technique as a criterion. We only included people who met one of the following criteria:

(1) individuals who are members of the LGBTI community who are 'out or outed' (that is, a person who is either living openly as an LGBTI individual or who is openly identified by 
the university community as such based on gender identity or behaviour)

(2) individuals who have knowledge about the Vhavenda culture in relation to gender identity and sexual orientation

We had two sets of samples. The first set, which we used for individual interviews, consisted of 15 individuals (five LGBTI individuals, three heterosexual students, four heterosexual staff members and three community members). A second set, who were involved in focus group discussions, was composed of two heterogeneous groups of six and five knowledge holders.

\section{Data collection}

We collected data in May and June 2015, using semi-structured individual interviews and focus group discussions. Our first interview participant was a transgender male to female individual, who has experienced a lot of stigma and discrimination on campus. Based on the analysis of the interview, which was occurring iteratively with data collection, we developed an interview guide which we used as probes and prompts for the individual interviews and focus group discussions. (See Appendix 1)

We initiated all the other interviews using either one of the following two central questions, depending on the group to which the participant belonged. For LGBTI individuals, the central question was: 'Kindly share with us your experiences as a member of the LGBTI community at this university?' For non-LGBTI members, the question was: 'What are your views concerning LGBTI individuals?’

We used probes and prompts based on the individual's response to create a discourse on deconstructing LGBTI and matula. We engaged 2 heterogeneous groups of six and five knowledge holders. The groups consisted of people, young and old and who held different positions on LGBTI and matula. We audio-recorded the interviews and the focus group discussions and also jotted down field notes pertaining to other aspects which couldn't be audio recorded.

\section{Data analysis}

We analysed data using narrative analysis. We undertook the following steps for analysis as described in Kobus (2007):

(1) transcribed each audio-recorded interview verbatim

(2) read and re-read each narrative in order to understand narrative strings running through 
each transcript

(3) identified commonalities running across all the transcripts

(4) identified the major themes/narrative threads

(5) finally, we identified the special themes.

\section{RESULTS}

The following special themes emerged from the data analysis:

(1) definition of culture and matula

(2) the construction of the concept of matula

(3) Christian values, interpretations and influence

(4) the tendency to sexualise identity

(5) knowledge of people about the salient reality of many truths.

\section{Definitions}

To do justice to this article there is a need to put it into context. After much debate and recording of what people thought about what LGBTI entails, we resolved to use the simple definitions below to engage colleagues and students as well as community members.

1. Lesbian refers to a female, woman or girl, who is physically, emotionally and sexually attracted to members of the same sex.

2. Gay refers to a male, man or boy, who is physically, emotionally and sexually attracted to members of the same sex.

3. Bisexual is an individual who may be attracted physically, emotionally and sexually to members of both the same or different sex (men and women).

4. Transgender relates to a person who is typically born with a biological sex that fits the norm for the male or female and then grows up to identify with the opposite gender. This means that the person's self-identity does not conform unambiguously to conventional notions of male or female gender. In fact it is a state of one's gender identity or gender expression not matching one's assigned sex. These people are usually born with typical male or female anatomies, but feel as though they have been born 'into the wrong body'.

5. Intersex means not obviously being male or female. Sometimes intersex people do not become aware of their status until they are teenagers, when puberty doesn't happen as expected. 


\section{The construction of the concept of matula}

We noted that when we introduced the topic and the related concepts, it was not uncommon for the people to not know what LGBTI stands for. They would ask: 'What is LGBTI?' They were the group that supposedly have never heard of the acronym LGBTI. We also noted that some of them were $\mathrm{PhD}$ students, who also worked in positions of influence in relation to learners, students and youth in general. We noted at that point that the lack of knowledge and understanding of who the LGBTI community was, actually suggested some level of ignorance. So we had to clarify what our own intentions were for doing research on this topic and, in clarifying our intentions, we grappled with the question of whether the research was necessary. After all, there are still some people who do not know what LGBTI stands for. We constantly debated the subject and recruited members to the debate. We subscribed to the principle that issues of minority concern are issues of everyone's concern - we cannot nullify it. The argument is still what we represent and it's still work in progress.

A pertinent question is why the LGBTI community is somewhat unacceptable at institutions of higher learning. Mention has been made already that the practice is considered as a taboo (matula). In an interview, one indigenous knowledge holder stated, 'a taboo is a fervent injunction of an action based on the belief that such behaviour is either too sacred or too ill-fated for ordinary individuals to undertake, under threat of supernatural punishment'. Such prohibitions are found in almost all societies. Taboos may relate to a human activity or custom that is prohibited based on moral judgment and religious beliefs. If one does an activity that is objectionable to society, he/she is said to have broken a taboo and this may lead to serious consequences such as imprisonment and social exclusion or ostracism. That may also bring embarrassment, humiliation and vulgarity.

Anthropologists have written extensively about taboos and there was a point where taboos were said to be universal. This was also enunciated by Freud, who stated that there are two universal taboos, namely incest and patricide, which formed the eventual basis of modern society, but that has been disputed by modern research. Modern research has shown that the idea of a universal taboo is questionable; however, there are some taboos, such as cannibalism, incest and genocide that occur in the majority of societies. Despite the fact that there isn't a universal taboo, certain or particular acts are prohibited and this is indicative of the fact that humanity in totality desires to be virtuous. Taboos in most societies range from dietary restrictions, restrictions on sexual activities and relationships, restrictions of bodily functions, exposure of body parts, nakedness and restrictions on the use of offensive language. 
Here we use R's story - which resonated with our own experiences of what we constantly hear in the community, to explain how we ended up with matula as a key concept of analysis in relation to LGBTI,

Whenever I walked around, I heard people calling 'Mme ya vhana matula', these were the first Venda words that I learned because the majority of people around here said that whenever I walked around. I later got to learn that a man who cross dresses and behaves in an effeminate way was seen as a taboo and that is what Venda people see in me. Matula, a taboo, because I do not conform to gender binaries and cultural norms. I thought since the university had taken on the role to implement the project on campus this was contradicting with what was said on social media about Univen being a hotbed of homophobia. I thought the university community embraced the programme, but only to find out that it was only few people who did, the majority of people are still stiff when it comes to the sexual diversity topic. I often come across situations where staff members would not even greet me back when I require assistance from their offices (this is all staff members), some would provide the services required in a non-friendly manner. Is being gay so bad that people would go to an extent of making comments about gay and lesbians deserving death because they have sinned?

With the rest of the participants, we started the conversation by asking the question: 'What is your view of the LGBTI community?' The following is how one of the focus group discussion participants responded:

This thing mentioned in the topic in question are generally wrong according to the laws laid out by the God we worship. But according to manmade laws are acceptable. What we need to think about is positively about love. But God wants a couple to give birth, that's what's frustrates our God that how are such people going to have children. If it's not about making children and families, it would be morally acceptable because loving one another is not a problem. Therefore I say it's wrong on the fact of making children and right on the fact that love is what we can't live without.

'muita zwivhuya khaite zwivhuya muita vhuvhi adi isa phanda zwothe zwido vhonala nga duvha lazwo' [Literally meaning: 'Let the sinner continue committing sins, it will be seen on judgement day ...']

\section{Christian values, interpretations and influence}

In the interviews, students expressed their opinions on the issue of LGBTI and the concept of matula (taboo). Most of the comments were primarily informed by religious affiliation. To be more precise, the Christian participants were the ones who were at the forefront when it came to condemning the LGBTI community. Christian thinking is conditioned by values and principles outlined in the Bible. Using the Bible as their guiding principle, some student participants had this to say:

Only the devil and his demons can try to change the plans of God. Everything God created was good and perfect according to his plan. This sin of LGBTI is making God vomit, because it's against nature. If God is not going to destroy this earth because of this sin, then He has to raise up people of Sodom and Gomorrah and apologise to them.

What happen to Sodom and Gomorrah? Is God mistaken to create man and woman? Why didn't he create another man to keep Adam busy so he won't be bored? It is said that man shall become 
one with his wife. Biblically a marriage is acceptable before the face of God.

The two comments above show that Christian thinking about LGBTI is based more on socially constructed notions that are basically informed by what the Bible says. The second comment emanated from the book of Genesis 19:1-11 (King James Version, 1611). Critically speaking, one can conclude that since creation, there has been LGBTI people, but like anything else that would be considered 'matula', such people were suppressed and refused to be free to express themselves like everyone else. Religion, as one of the contributing factors of social constructivism, has shaped how people think and how they view the LGBTI community.

The studies conducted by Mavhandu-Mudzusi and Sandy (2015) indicated that religionrelated stigma and discrimination are common at a rural based university in South Africa. Lesbian, gay, bisexual, transgender and intersex students are typically ascribed a range of labels, including 'sinners', 'devils' and 'demon possessed'. Some of these comments were encountered during an interview:

According to my life and my experience, when I was growing up, everything we do was based on God's will so this LGBTI thing is not wrong, but forbidden by Jesus. I know you will stand for it, because what you love is what Jesus hate.

Though our intention is not to be biased, the research revealed that most of the participants who are non-Christians, showed more tolerance towards the LGBTI community. One of the participant commented in this way:

I don't read the Bible, hence, I see nothing wrong with being LGBTI. I am not a gay, but I might give birth to a LGBTI child. So I don't judge at all. They didn't choose to be like that and I didn't choose to be straight, but am happy am straight

Some students tried to comprehend the phenomenon of LGBTI from a social constructivist point of view. Some of the students, whose thinking was shaped by the social constructivism approach, had this to say:

It is a shared fact that we all have sexual orientation and a gender identity. That is why anything outside this norm is considered a taboo (I think you call it 'matula-matudzi' in Tshivenda?). Actually my sense is that being LGBTI is a sin in most if not all the communities in South Africa. My view is that the LGBTI as a community has what is called identity crisis which is an issue that transcends the LGBTIs and actually affects all of us. South Africa as a democratic country has a very complex and diverse culture, in particular the history of LGBTIs and its human rights.

I think this idea of judging homosexual people and discriminating against them on the basis of what your religion says is stupid and farfetched. The point that I want to make is we are all humans and have the right to dignity and not to be unfairly discriminated against, whether it be 
on the basis of gender, sexual orientation or race. Those who speak against homosexual people and perpetuate hatred towards them using religion or other means of justification for such acts are not different from the architects of apartheid; the common feature being discrimination against people. Let people be who they want to be!

Another respondent said:

This thing of LGBTI is no longer out of ordinary in the world of today. Therefore one cannot say it's bad or 'matudzi'. One has a right to choose what they want and what they want to be; however, I see nothing wrong about people practicing gay marriage, for instance. As long as they aren't breaking any law, let them enjoy what they think is good for them.

Though some can justify their homophobic stances on the basis of religion, they tend to violate the rights of the LGBTI community. The justification that they offer is, to some extent, invalid to those who do not subscribe to religion.

It is not about hate man, being LGBTI, it's wrong because it is against nature. We should be having gay animals also and the worst part is, it is going to block continuity of our race. Our economy real needs a rise in population so that it could recover, companies are withdrawing from investing in S.A as a result of less population, because gays and lesbians don't give birth and their rate it is increasing each and every day.

Based on the above comments, it is of paramount importance for society to deconstruct some of the values and principles prescribed by religion. This does not mean that the Bible is not relevant, it was relevant many centuries ago and it is still relevant in the contemporary world, but there must be a tolerance and acceptance of diversity in people.

\section{The tendency to sexualise identity}

Sometimes societal definitions are not all inclusive. What one feels inside is not necessarily always be congruent to the sex that the person is understood to be. The tendency therefore to define people according to their sex in this regard is problematic. We explain our experiences and contestations of an ascribed sexual identity by mentioning the experiences of Nndwayamato and Nndwakhulu (fictional names), two young boys who were born and raised in a village. We argue that none of the definitions ascribed to the boys by the community fits their experience of their identity, at least not from what they tell us and what we have observed about how they have lived their lives over the years. This has to do with identity politics. Identity politics are political arguments that focus upon the interest and perspectives of groups with which people identify. It also includes the ways in which people's politics may be shaped by aspects of their identity through loosely correlated social organisations. 
Nndwayamato was born in a traditional African Zionist church family. His grandfather was a founding bishop. He was raised by his grandparents and members of the extended family. He had an absent father, who later died when Nndwayamato was 13 . His mother died when he was 3 years old. When he was between 10 and 11 years old, he started showing a preference to dress in a feminine way, he liked nail polish and lipstick. He also liked dancing, which he still does today. He is a member of a traditional women's dance group. Should we call him transgender? Hmm, but it sounds like too big a name for him. He is just a boy! Yet, he has suffered discrimination, and has been made to feel abnormal and rejected by people who should be embracing his diversity.

Nndwakhulu, also born and raised in a rural Venda village, grew up in a typical traditional Vhavenda family, who was poor, but knew how to thrive. He too joined the women's dance group and the community knew that they were friends. 'We are just friends', they continuously had to account to an insensitive, judgmental community, who assumed that they had a sexual relationship. In fact, Nndwamato, who is more outspoken, has shared with one of us (researchers) information about his girlfriend; how he wants to work hard, get married, have a white wedding, et cetera.

\section{The tendency to homogenise LGBTI groups}

During the study, we realised the more we interacted with and read about LGBTI individuals, the more we learned about their diversity. We learnt that although they share the common experience of stigmatisation due to sexual orientation, gender identity or gender expression, the LGBTI community is a multidimensional group with unique variations differentiated by ethnicity, socioeconomic status and other characteristics. They, like all of humanity, are different. So, with this understanding, we went out to solicit evidence in this regard.

Literature teaches us that scholars have been concerned about the effects and consequences of representation and its 'politics' for a long time (Hall and Nixon 2013) and that knowledge production discourses are necessary to understand the origins and meaning of words or definitions. 'LGBTI community should not have to be treated as a homogenous group because they are not, they do not have to'. These were the words of one participant during our interviews. I sometimes feel there is an obsession to place people in boxes, no one asks why non LGBTI community are defined as they are defined.

\section{People know the salient reality of many truths}

It was also evident from the focus groups that even amongst the supposed homogenous group 
in terms of religion, the difficult questions emerged. We learnt that even among the sceptics, there is an inherent noise that allows us to ask ourselves the tough questions. One respondent said: 'By the way, who determines if it is blue or pink? Is a boy/girl child not just a child? Why the description by the way?'

Respondent S, said,

Is LGBTIs a question of biological disorder, choice, identity crisis, social culturalisation that has gone wrong or right, who is to be blamed?

By the way biology always assigns YY chromosomes or XY chromosomes and worst cases YYX or XXY chromosomes ... mhm!!!!!

There is a wealth of discussions about multiple truth, multiple realities, and the dominant paradigms. Society today is driven by the belief that there is only one truth in the world, and once that truth is discovered all things can be determined from that truth. If there is only one truth then everything else must be false. And since truth is good, then error is evil. In the context of the study, we felt such discussions will have to be part of the education, advocacy and more research.

\section{DISCUSSION}

From the interactions we had with participants in the study, it became clear that deconstructing the concept of normal was the starting point and that it would require a strategy and a greater amount of time than we had anticipated. As anticipated, the strategy included examining identity politics in order to encourage diversity. The expression 'identity politics' has been discussed several times to generate new ways of identity representation rather than the bipolar gender system. To debunk stereotypes, the sharing of information, as well as educating and the generating of knowledge, is necessary. As reflected in some of the narratives of participants, there are some people who are LGBTI-phobic, only because they do not have enough information about LGBTI. Butler (1990) for example, stresses the importance of not assuming an already existing identity, but of remaking and unmaking identities through performance.

From the discussions that ensued, one may confirm the saying that human behaviour is not governed only by rational decision making. It is a fact that societies have values that are shared and behaviours that are regarded as acceptable and these behaviours are agreed upon by members of the society. Deviance of these behaviours and norms has an effect on one's life. Society is not static and, therefore, culture cannot be static. One cultural characteristic is that culture changes and, as it changes, we have to adapt to those changes. Cultural activities such 
as the way we eat, interact with each other, as well as our sex life, are governed by norms and taboos and these norms and taboos are not static; it is forever changing. Some taboos may be weakened or even disappear, while others may become stronger and more dominant.

Universities have a responsibility to spearhead and to be exemplary in terms of creating spaces for debates about challenging oppressive and unjust tendencies including those that maybe deeply rooted in people's beliefs and practices. When universities do not engage on these matters, they tend to mirror oppressive culture and religious based tendencies in the communities which is an indictment as universities are supposed to provide spaces for critical thinking and reflection. This then leads to a disgruntled unhappy and dysfunctional society. As stated by Gitterman and Shulman (1994, 11), more than a decade ago already, repeated exposure to oppression subtle or direct, may lead vulnerable members of the oppressed group to internalize the negative self images projected by the external oppressor - the oppressor without.

Furthermore, there seems to be a gap between our education system and the South African Constitution. South Africa's post-apartheid Constitution was the first in the world to outlaw discrimination based on sexual orientation. In the Bill of Rights, every child has a right to education and it is in the education system that children are socialised. To date, universities that are still silent about accommodating LGBTI individual needs can still get away with it for the longest time whilst the LGBTI individuals continues to be ridiculed and discriminated upon. Furthermore, Reygan (2013) says that there is a need for schools to teach anti-oppressive pedagogies in relation to sexual and gender minorities in education. Socialisation is a lifelong process during which we learn about social expectations and how to interact with other people. It is during this socialisation process that we acquire behavioural norms that help us fit with our society. This is where young adults need to be conscientised about sexuality, so that they can learn to accept each other. This will assist them, as members of the community, in embracing LGBTIs and to not consider the behaviour of the LGBTI as aberrant. Poor sexual education also translates to higher institutions, where homophobia is also a reality. This will also demystify the preconceived idea of heterosexuality.

We consider that unless stricter recourse are imposed at universities, discriminatory practices will continue to render LGBTI individuals inhumane. Stricter, tighter monitoring and evaluation processes are necessary. It is a function of a university in rural settings more than in other areas to create spaces for intergenerational debates and education on such topics as taboos, culture, diverse sexual orientations, the bill of rights enshrined in the constitution and other related subjects. Universities should apply principles of distributive justice - 'how a society or 
group should allocate its scarce resources or product among individuals with competing needs or claims' (Roemer 1996, 1). Theories of distributive justice enable discussions about what constitutes a socially just manner of distribution and about what kinds of LGBTI arrangements should be defended (Rawls 1971). Unfortunately, such debates is still lacking in universities and communities at large. Furthermore, trends for self-alienation and internalized oppression are also apparent due to a lack internal access to healthy modes of resistance by LGBTI individual (Fanon 2004). Also by equipping students with skills to challenge inequality and discrimination in their study environment, making certain that the learning materials do not promote discrimination against any individuals or groups as well ensuring policies, procedures and processes do not discriminate (Francis 2012; Francis and DePalma, 2014).

The concept of diversity includes recognition and respect. It means understanding that each individual is unique and identifying our individual differences. These can be along the dimensions of race, ethnicity, gender, sexual orientation, socioeconomic status, age, physical abilities, religious beliefs, political beliefs or other ideologies. It is about understanding each other and moving beyond simple tolerance to embracing and celebrating the rich dimensions of diversity contained within each individual.

\section{CONCLUSION}

The first phase of the study enabled the researchers to clarify the starting point of this research process and outline the context. It also provided evidence to confirm the inherent stigma and alienation of the LGBTI community in the context of the study. We were able to show our own discomfort about the names and labels and argue that the general assumptions that the LGBTI is a homogenous group and that they will seamlessly fit the definitions provided, is problematic. We learnt that deconstructing the term matula would require a continuous and consistent process of dialogue. This article is thus a starting point of a very long inclusive dialogue and questioning matula as a troubling concept that is often at the centre of the responses of stigma towards the LGBTI community.

Some taboos are interpersonal, for example, those that relate to human sexuality such as homosexuality, transvestites and bestiality, among others. Taboos are widely agreed upon and generally viewed as negative entities that are to be avoided and evaded. As people's morals and values are different, so too are the taboos they believe in. There are taboos on every subject and they vary from culture to culture. What unites these different ideas is the quest for knowledge about what is right or what is wrong. This mission links people of all ideologies in an attempt to better themselves and create a morally just human race that is tolerant of each other's 
diversity. In this regard, universities have an important role to play. By promoting diversity, universities will continue to bring to the fore that cultures, and therefore taboos are socially constructed and therefore not static. Universities should facilitate a process where it is okay to challenge, debate oppressive cultural taboos - matula, norms and values. As outlined, earlier in the discussion, most of the beliefs and religiousity are actually based on lack of knowledge, awareness and critical collective consciousness. Without some kind of engagement about what matula actually mean and come from, the likelihood of such communities to question it on themselves is close to none. In this regard, intergenerational education is crucial. Students who are in these universities come from the very communities that teaches them about matula. We thus agree with the notion that if you want to get a word out to the communities faster, educate the children and youth in the society. The universities community, students and staff, are vehicles in advancing the debates and promoting diversity and therefore it is incumbent upon universities to provide spaces for education and learning on these matters.

\section{Limitations}

The application of the narrative approach means that the findings are not generalisable however the article provided an opportunity to scratch the surface of a much needed debate on issues affecting the LGBTIs as a marginalised group.

\section{Recommendations}

We recommend further studies focusing specifically on mechanisms that will facilitate 'normalisation' of discussions about LGBTI in the context of beliefs, culture and religion and to interrogate the process of constructing a category of stereotype such as matula. The notions of right and wrong need to be interrogated amongst the communities. The debates about binaries, what is right and wrong, and who determines the 'right' and 'wrong' seem to be taking place at academic levels.

Open discussions about the LGBTI community on university grounds is necessary. Universities as socialising agents should play a role on deconstructing heteronormativity within the context of people's beliefs in 'matula'. However, there are other important socialising institutions such as families and community structures that must be brought on board. The universities thus play an important role in facilitating the discussions.

\section{ACKNOWLEDGEMENTS}

The team would like to thank the following people: 
- $\quad$ Sponsors and leadership from Wits

- Smakaleng Mothapo for his generous contribution

- $\quad$ All the students who participated in the study

\section{REFERENCES}

Arndt, M. and G. P. de Bruin. 2006. Attitudes toward lesbians and gay men: Relations with gender, race and religion among university students. Psychology in Society 33: 16-30.

Brouard, P. and J. Pieterse. 2012. One step forward, two steps backward: Equality and sexual orientation in South Africa 2009-2011. In South African Human Rights Commission equality report: commentaries on equality: race, gender, disability and LGBTI Issues, 49-63. Braamfontein: South African Human Rights Commission.

Butler, J. 1990. Gender trouble: Feminism and the subversion of identity. Routledge: New York.

Collins, D. 2009. 'We're there and queer': Homonormative mobility and lived experience among gay expatriates in Manila. Gender \& Society 23(4): 465-493.

DeBarros, L. 2014. SA University a hotbed of homophobia? http://www.mambaonline.com/2014/ 02/18/sa-university-a-hotbed-of homophobia/ (accessed on 19 February 2014).

Fanon, F. 2004. The wretched of the earth. New York: Grove Press.

Francis, D. 2012. Teacher positioning on the teaching of sexual diversity in South African schools. Culture, Health \& Sexuality 14(6): 597-611.

Francis, D. 2013. 'You know the homophobic stuff is not in me, like us, it's out there'. Using Participatory Theatre to challenge heterosexism and heteronormativity in a South African school. South African Journal of Education 33(4): 1-14.

Francis, D. and R. DePalma. 2014. Teacher perspectives on abstinence and safe sex education in South Africa. Sex Education: Sexuality, Society and Learning 14(1): 81-94.

Francis, D. and T. Msibi. 2011. Teaching about heterosexism: Challenging homophobia in South Africa. Journal of LGBT Youth 8(2): 157-173.

Gitterman, A. and L. Shulman. (Eds.). 1994. Mutual aid groups, vulnerable populations and the life cycle. New York: Columbia University Press.

Hall, S., J. Evans and S. Nixon. 2013. Representation. $2^{\text {nd }}$ Edition. London: Sage.

Hardiman, R. and B. W. Jackson. 1997. Conceptual foundations for social justice courses. In Teaching for diversity and social justice: A sourcebook, ed. M. Adams, L. A. Bell and P. Griffin, 16-29. New York: Routledge.

Human Rights Watch. 2009. Together, apart, organizing around sexual orientation and gender identity worldwide. New York, NY: Human Rights Watch.

Human Rights Watch. 2011. We'll show you you're a woman. Violence and discrimination against black lesbians and transgender men in South Africa. New York, NY: Human Rights Watch.

Kobus, M. 2007. First step in research. Pretoria: Van Schaik publishers.

Mavhandu-Mudzusi, A. H. 2014. Experiences of lesbian, gay, bisexual, transgender and intersex students regarding sports participation in a South African rural-based university. African Journal for Physical, Health Education, Recreation and Dance 20(2.2): 710-720.

Mavhandu-Mudzusi, A. H. and R. M. Ganga-Limando. 2014. Being lesbian, gay, bisexual, transgender and intersex (LGBTI) students in a South African university: Implications for HIV prevention. African Journal of Nursing and Midwifery 16(2): 125-138.

Mavhandu-Mudzusi, A. H. and V.O. Netshandama. 2013. Attitudes of students towards the lesbian, gay, bisexual, transgender and intersex community: A case of a South African, rural-based university. African Journal for Physical, Health Education, Recreation and Dance 1(1): 56-66. 
Mavhandu-Mudzusi, A. H. and P. T. Sandy. 2015. Religion-related stigma and discrimination experienced by lesbian, gay, bisexual and transgender students at a South African rural-based university. Culture, Health \& Sexuality: An International Journal for Research, Intervention and Care 17(8): 1049-1056.

Mostert, H. P., C. Myburgh and M. Poggenpoel. 2012. Learners’ perceptions towards learners regarded as having a homosexual orientation in an independent secondary school environment. Curationis 35(1), Art. \#24, 7 pages. http://dx.doi. org/10.4102/curationis.v35i1.24

Müller, A. 2013. Teaching lesbian, gay, bisexual and transgender health in a South African health sciences faculty: Addressing the gap. BMC Medical Education 13(174): 1-7.

Rawls, John. 1971. A theory of justice. Cambridge, MA: Belknap Press of Harvard University Press.

Republic of South Africa. 1996. Constitution of the Republic of South Africa, 1996. Pretoria: Government Printer.

Reygan, F. 2012. LGBTI affirming educational practice: Developing anti-homophobic bullying materials. Journal of Educational Studies 12(1): 229-239.

Reygan, F. and D. Francis. 2015. Emotions and pedagogies of discomfort: Teachers' responses to sexual and gender diversity in the Free State, South Africa. Education as Change 19(1): 101-119. DOI: 10.1080/16823206.2014.943259

Rispel, L. C., A. Cloete, C. A. Metcalf, K. Moody and G. Caswell. 2012. 'It [HIV] is part of the relationship': Exploring communication among HIV-serodiscordant couples in South Africa and Tanzania. Cult Health Sex 14: 257-268.

Roemer, John E. 1996. Theories of distributive justice. Cambridge, MA: Harvard University Press.

Taylor, Y. and R. Snowdon. 2014. Making space for young lesbians in church? Intersectional sites, scripts, and sticking points. Journal of Lesbian Studies 18: 393-414. 


\section{Appendix 1}

\section{INTERVIEW GUIDE}

The interview guide consisted of the following questions:

(1) Kindly share with us your understanding of the concept LGBTI?

(2) What are your views concerning LGBTI individuals?

(3) What is your understanding of matula and how it relates with LGBTI?

(4) Why would you relate the LGBTI community with matula and matudzi?

(5) What forms the basis of your attitudes towards LGBTI individuals? 